\title{
Determinants of Cardiovascular Risk in Haemodialysis Patients: Post hoc Analyses of the AURORA Study
}

\author{
Andreas Schneider ${ }^{a}$ b $\quad$ Alan G. Jardine ${ }^{a} \quad$ Markus P. Schneider $^{a, g}$ \\ Hallvard Holdaas $^{c}$ Ingar Holme ${ }^{d}$ Bengt C. Fellstroem ${ }^{e}$ Faiez Zannad $^{f}$ \\ Roland E. Schmiederg on behalf of the AURORA Study Group \\ ${ }^{a}$ Renal Research Group, British Heart Foundation Cardiovascular Research Centre, Institute of Cardiovascular and \\ Medical Sciences, University of Glasgow, Glasgow, UK; ${ }^{b}$ Division of Nephrology, Department of Medicine, \\ University Hospital Würzburg, Würzburg, Germany; ${ }^{\circ}$ Medical Department, Rikshospitalet, University of Oslo, and \\ ${ }^{\mathrm{d}}$ Department of Preventive Cardiology, Centre of Preventive Medicine, Oslo University Hospital, Ullevål, \\ Oslo, Norway; ${ }^{\mathrm{e}}$ Renal Unit, Department of Medical Science, University Hospital, Uppsala, Sweden; ${ }^{\mathrm{f}}$ Department of \\ Cardiology, Centre d'Investigation Clinique 9501 and Unité 961, Nancy University, Nancy, France; ${ }^{9}$ Department of \\ Nephrology and Hypertension, University Hospital Erlangen, Erlangen, Germany
}

\section{Key Words}

Cardiovascular events · Haemodialysis · Epidemiology

\begin{abstract}
Background: Haemodialysis patients are at high risk for cardiovascular (CV) events. The aim of the current study was to characterise the role of traditional and uraemia-specific CV risk factors in this patient population. Methods: A post hoc analysis of the AURORA trial which enrolled 2,776 haemodialysis patients from 280 centres and had a mean follow-up period of 3.2 years. Determinants of CV endpoints (time to major cardiovascular event (MACE), cardiac event, CV death) were identified by univariate Cox regression analysis. Subsequently, independent determinants were identified by multivariate regression analysis. Results: For the primary endpoint MACE (myocardial infarction, stroke and cardiac death), multivariate analysis revealed that independent determinants were: age (hazard ratio (HR) 1.03 per year), serum phosphate level (HR 1.50 per $\mathrm{mmol} / \mathrm{l})$, albumin level (HR 0.94
\end{abstract}

per g/l), years on haemodialysis (HR 1.03 per year), diabetes mellitus (HR 1.38), preexisting coronary heart disease (HR 1.54) and C-reactive protein (CRP) level (HR 1.14 per $\mathrm{mg} / \mathrm{l}$ ). However, conventional risk factors such as smoking, dyslipidaemia, systolic and diastolic blood pressure and pulse pressure had no significant effect. Conclusions: Although we identify CRP, low albumin, and high phosphorus as risk factors for MACE, lowering CRP did not influence MACE outcomes in our trial. Caution is therefore warranted in implying risk factors being causal in end-stage renal disease.

Copyright $\odot 2013$ S. Karger AG, Basel

\section{Introduction}

In the general population, the most important risk factors for cardiovascular disease (CVD) include high blood pressure, smoking, diabetes, older age, male sex, obesity, preexisting coronary heart disease (CHD), and dyslipidaemia [1-6]. It is well established that in a population of

\section{KARGER}

E-Mail karger@karger.com

www.karger.com/ajn (c) 2013 S. Karger AG, Basel

$0250-8095 / 13 / 0372-0144 \$ 38.00 / 0$
Andreas Schneider, MD

Division of Nephrology, University of Würzburg Oberdürrbacherstrasse 6 DE-97080 Würzburg (Germany)

E-Mail schneider_a6@medizin.uni-wuerzburg.de 
patients receiving maintenance haemodialysis (HD), the prevalence of CVD and cardiovascular (CV) mortality are far greater than in the general population [7]. However, traditional CV risk factors do not explain the increased risk and interventions such as lipid lowering with statin therapy have no benefit in this population $[8,9]$, suggesting that the natural history and pathogenesis of CVD is different from the general population. In contrast, non-traditional, uraemia-related factors such as inflammation, low serum albumin levels, high serum phosphate, hyperparathyroidism (HPT) and vitamin D deficiency [10-15] have been associated with CVD in patients on maintenance HD. However, most of these studies had significant limitations, such as small sample size or observational study design.

AURORA (a study to evaluate the use of rosuvastatin in subjects on regular haemodialysis: an assessment of survival and CV events) is the largest randomised controlled trial conducted in HD patients, with blinded, independent adjudication of endpoints, in which 2,776 HD patients were followed up for 4 years. Although the study failed to show any benefit of rosuvastatin therapy, it provides a unique resource in which to study the determinants of CVD in patients receiving HD. Thus, in the present report we have analysed the impact of traditional and non-traditional CV risk factors on CV outcomes in a large population of HD patients who participated in the AURORA study.

\section{Materials and Methods}

\section{Design of the AURORA Study}

The AURORA study design, main outcome findings, and baseline data have been described previously [8]. In short, AURORA recruited 2,776 HD patients (treated with $\mathrm{HD}$ for at least 3 months), aged 50-80 years, from 280 nephrology centres in 25 countries. Eligible patients were randomly assigned to receive either rosuvastatin $10 \mathrm{mg}$ daily, or matching placebo. The mean length of follow-up was 3.2 years. Treatment with rosuvastatin was not associated with a reduction in the composite primary endpoint of major adverse cardiovascular events (MACE) [8].

CV endpoints in AURORA included (i) time to MACE, which was a combined endpoint of non-fatal myocardial infarction and non-fatal stroke and of death from all CV causes. Again, death from all $\mathrm{CV}$ causes was defined as death from CHD (definite), CHD (suspected), other cardiac cause, other vascular cause, other $\mathrm{CV}$ cause, ischemic stroke, unclassified stroke and primary intracerebral haemorrhage, cerebellar haemorrhage or both.

Further CV endpoints in AURORA were (ii) time to atherosclerotic cardiac event (including definite or probable non-fatal myocardial infarction, and deaths due to CHD), and (iii) CV death (including death from all CV causes). All events were reviewed and adjudicated by an independent endpoint committee blinded to

Table 1. Baseline demographic characteristics

Age, years

Female sex, n (\%)

BMI

Current smoker, n (\%)

Calcium, $\mathrm{mmol} / \mathrm{l}$

Phosphate, $\mathrm{mmol} / \mathrm{l}$

Albumin, g/l

$\mathrm{TC}, \mathrm{mmol} / \mathrm{l}$

HDL-C, mmol/l

LDL-C, $\mathrm{mmol} / \mathrm{l}$

Triglycerides, $\mathrm{mmol} / \mathrm{l}$

ApoB/ApoA-1 ratio

Oxidized LDL, mmol/l

Haematocrit ratio

Haemoglobin, g/l

$\mathrm{SBP}, \mathrm{mm} \mathrm{Hg}$

DBP, $\mathrm{mm} \mathrm{Hg}$

PP, mm Hg

Calculated Kt/V

On HD, years

Diabetes mellitus, n (\%)

History of CHD, n (\%)

Use of ACEi, n (\%)

Use of $\beta$-blocker, n (\%)

Use of sevelamer, $\mathrm{n}(\%)$

New centre, $n(\%)$

hsCRP, mg/l

$\log \mathrm{CRP}$
$64.2 \pm 8.7$
$1,050(37.9)$
$25.4 \pm 4.9$
429 (15.5)
$2.3 \pm 0.22$
$1.8 \pm 0.56$
$39.7 \pm 3.5$
$4.4 \pm 1.1$
$1.2 \pm 0.4$
$2.6 \pm 0.9$
$1.8 \pm 1.1$
$0.7 \pm 0.3$
$34 \pm 14$
$0.4 \pm 0.05$
$117 \pm 16$
$137 \pm 24$
$76 \pm 13$
$61 \pm 19$
$1.2 \pm 0.3$
$3.5 \pm 3.8$
731 (26.4)
$1,424(51.4)$
$1,020(36.8)$
$1,032(37.4)$
$506(18.3)$
718 (25.9)
$5.0(2.0-14.4)$
$1.6 \pm 1.3$

The body mass index (BMI) is the weight in kilograms divided by the square of the height in meters. Values are presented as mean $\pm \mathrm{SD}$ or median (interquartile range), unless otherwise indicated.

$\mathrm{TC}=$ Total cholesterol; HDL = high-density lipoprotein; $\mathrm{LDL}=$ low-density lipoprotein; ApoB/ApoA-1 = ratio of apolipoprotein $\mathrm{B}$ and apolipoprotein $\mathrm{A}-1$; $\mathrm{SBP}=$ systolic blood pressure; $\mathrm{DBP}=$ diastolic blood pressure; $\mathrm{PP}=$ pulse pressure; $\mathrm{Kt} / \mathrm{V}=$ dialyzer clearance of urea and dialysis time divided with volume of distribution of urea; $\mathrm{CHD}=$ coronary heart disease; $\mathrm{CRP}=\mathrm{C}$-reactive protein.

treatment allocation [8]. The study adhered to the International Conference on Harmonisation Guidelines for Good Clinical Practice and was conducted in accordance with the Declaration of Helsinki. All participants provided written informed consent, and the ethics committee at each participating centre approved the trial.

\section{Risk Factor Analysis}

All analyses were conducted using SAS statistics (SAS Institute, Cary, N.C., USA). The current risk factor analysis was conducted in both treatment arms combined, as there were no significant differences in CV events between the two treatment groups [8]. Potential risk factors included demographic characteristics (age, sex, body mass index (BMI), smoking, years on $\mathrm{HD}, \mathrm{Kt} / \mathrm{V})$; co-morbid 
Table 2. Risk factors for MACE: uni- and multivariate analyses

\begin{tabular}{|c|c|c|c|c|}
\hline Variable & $\begin{array}{l}\text { Univariate HR } \\
\text { (95\% CI for HR) }\end{array}$ & $\mathrm{p}$ & $\begin{array}{l}\text { Multivariate HR } \\
\text { (95\% CI for HR) }\end{array}$ & $\mathrm{p}$ \\
\hline Age (per year) & $1.04(1.03-1.05)$ & $<0.001$ & $1.03(1.02-1.04)$ & $<0.001$ \\
\hline Female sex & $1.09(0.95-1.26)$ & 0.221 & & \\
\hline BMI & $1.01(0.99-1.02)$ & 0.405 & & \\
\hline Current smoker & $1.07(0.89-1.29)$ & 0.463 & & \\
\hline Calcium (mmol/l) & $0.73(0.53-1.01)$ & 0.060 & & \\
\hline Phosphate (mmol/l) & $1.30(1.15-1.48)$ & $<0.001$ & $1.50(1.31-1.70)$ & $<0.001$ \\
\hline Albumin (g/l) & $0.92(0.90-0.94)$ & $<0.001$ & $0.94(0.92-0.96)$ & $<0.001$ \\
\hline $\mathrm{TC}(1.3 \mathrm{mmol} / \mathrm{l})$ & $0.92(0.86-0.98)$ & 0.013 & & \\
\hline HDL-C (1.3 mmol/l) & $0.86(0.72-1.04)$ & 0.113 & & \\
\hline LDL-C (1.3 mmol/l) & $0.94(0.87-1.02)$ & 0.155 & & \\
\hline Triglycerides $(0.6 \mathrm{mmol} / \mathrm{l})$ & $0.93(0.87-0.99)$ & 0.040 & & \\
\hline ApoB/ApoA-1 ratio & $1.18(0.90-1.60)$ & 0.239 & & \\
\hline ApoB (mg/dl) & $0.92(0.69-1.23)$ & 0.567 & & \\
\hline ApoA-1 (mg/dl) & $0.63(0.48-0.82)$ & 0.001 & & \\
\hline Oxidized LDL (mmol/l) & $0.99(0.99-1.00)$ & 0.326 & & \\
\hline Haematocrit ratio & $0.22(0.05-0.93)$ & 0.040 & & \\
\hline Haemoglobin (g/l) & $0.99(0.99-1.00)$ & 0.007 & & \\
\hline $\mathrm{SBP}(\mathrm{mm} \mathrm{Hg})$ & $1.00(0.99-1.00)$ & 0.137 & & \\
\hline DBP (mm Hg) & $0.99(0.99-1.00)$ & 0.018 & & \\
\hline $\mathrm{PP}(\mathrm{mm} \mathrm{Hg})$ & $1.00(1.00-1.01)$ & 0.001 & & \\
\hline Calculated Kt/V & $0.78(0.60-1.00)$ & 0.049 & & \\
\hline On HD (per year) & $1.02(1.00-1.03)$ & 0.046 & $1.03(1.01-1.05)$ & 0.002 \\
\hline Diabetes mellitus & $1.70(1.46-1.96)$ & $<0.001$ & $1.38(1.14-1.67)$ & 0.001 \\
\hline History of CHD & $2.05(1.77-2.37)$ & $<0.001$ & $1.54(1.28-1.85)$ & $<0.001$ \\
\hline Use of ACEi & $1.12(0.97-1.29)$ & 0.111 & & \\
\hline Use of $\beta$-blocker & $1.04(0.90-1.20)$ & 0.575 & & \\
\hline Use of sevelamer & $0.88(0.73-1.05)$ & 0.159 & & \\
\hline New centre & $0.78(0.65-0.92)$ & 0.004 & & \\
\hline hsCRP (mg/l) & $1.02(1.01-1.02)$ & $<0.001$ & & \\
\hline $\log \mathrm{CRP}$ & $1.21(1.15-1.28)$ & $<0.001$ & $1.14(1.07-1.20)$ & $<0.001$ \\
\hline
\end{tabular}

disease (diabetes mellitus, preexisting CHD); systolic (SBP) and diastolic (DBP) blood pressure, or pulse pressure (PP); information on use of concomitant medication (ACE inhibitors (ACEi), $\beta$-blocker, sevelamer); baseline routine laboratory assessments (haematocrit, haemoglobin, and serum calcium, phosphate, albumin, total cholesterol (TC), high-density lipoprotein cholesterol (HDL-C), low-density lipoprotein cholesterol (LDL-C), triglyceride), and non-routinely used biomarkers (apolipoprotein-A1 (ApoA-1) and apolipoprotein-B (ApoB), oxidatively modified low-density cholesterol (OX-LDL), highly sensitive C-reactive protein (hsCRP)) (table 1).

Determinants of CV endpoints were identified first by univariate Cox regression analysis, then hazard ratios (HR) with $95 \%$ confidence intervals and $\mathrm{p}$ values were generated for independent risk factors by using a stepwise Cox regression analysis. For parameters that were closely related (e.g. haemoglobin and haematocrit, PP and SBP or DBP, or ApoA-1 and HDL-C), single variables were inserted to identify the best fit in the multivariate analysis. Several potential risk factors were analysed for each outcome before model building. In the Cox multivariate model, the p value for inclusion and exclusion was set at 0.01 .
Further, variable importance for MACE was calculated by using a random survival forest (RSF) model. RSF modelling reduces variance and bias by using all variables collected and assessing for non-linear effects and complex interactions.

\section{Results}

To identify CV risk factors in patients receiving maintenance $\mathrm{HD}$, we analysed three major $\mathrm{CV}$ endpoints: MACE, atherosclerotic cardiac events and CV death (tables 2-4).

\section{Time to Major CV Event}

In AURORA, the primary endpoint of MACE was recorded in 804 patients (18.7 events per 100 patient-years). The major univariate risk factors for this endpoint were age (HR 1.04), phosphate (HR 1.30), albumin (HR 0.92), 
Table 3. Risk factors for cardiac event: uni- and multivariate analyses

\begin{tabular}{|c|c|c|c|c|}
\hline Variable & $\begin{array}{l}\text { Univariate HR } \\
\text { (95\% CI for HR) }\end{array}$ & $\mathrm{p}$ & $\begin{array}{l}\text { Multivariate HR } \\
\text { (95\% CI for HR) }\end{array}$ & $\mathrm{p}$ \\
\hline Age (per year) & $1.04(1.03-1.05)$ & $<0.001$ & $1.03(1.02-1.04)$ & $<0.001$ \\
\hline Female sex & $1.22(1.02-1.46)$ & 0.034 & & \\
\hline BMI & $1.01(0.99-1.02)$ & 0.572 & & \\
\hline Current smoker & $1.10(0.87-1.38)$ & 0.444 & & \\
\hline Calcium (mmol/l) & $0.65(0.44-0.97)$ & 0.036 & & \\
\hline Phosphate (mmol/l) & $1.26(1.08-1.47)$ & 0.003 & $1.42(1.21-1.67)$ & $<0.001$ \\
\hline Albumin $(g / l)$ & $0.92(0.90-0.95)$ & $<0.001$ & $0.96(0.93-0.98)$ & 0.002 \\
\hline $\mathrm{TC}(1.3 \mathrm{mmol} / \mathrm{l})$ & $0.94(0.87-0.98)$ & 0.013 & & \\
\hline HDL-C (1.3 mmol/l) & $0.77(0.60-0.97)$ & 0.025 & & \\
\hline LDL-C (1.3 mmol/l) & $0.97(0.88-1.07)$ & 0.546 & & \\
\hline Triglycerides $(0.6 \mathrm{mmol} / \mathrm{l})$ & $0.96(0.89-1.05)$ & 0.369 & & \\
\hline ApoB/ApoA-1 ratio & $1.46(1.04-2.04)$ & 0.027 & & \\
\hline ApoB (mg/dl) & $0.97(0.67-1.38)$ & 0.845 & & \\
\hline ApoA-1 (mg/dl) & $0.48(0.34-0.67)$ & $<0.001$ & $0.60(0.41-0.87)$ & 0.007 \\
\hline Oxidized LDL (mmol/l) & $0.99(0.99-1.00)$ & 0.105 & & \\
\hline Haematocrit ratio & $0.21(0.34-1.29)$ & 0.092 & & \\
\hline Haemoglobin (g/l) & $0.99(0.99-1.00)$ & 0.024 & & \\
\hline $\mathrm{SBP}(\mathrm{mm} \mathrm{Hg})$ & $1.00(0.99-1.00)$ & 0.990 & & \\
\hline $\mathrm{DBP}(\mathrm{mm} \mathrm{Hg})$ & $0.99(0.98-1.00)$ & 0.002 & & \\
\hline $\mathrm{PP}(\mathrm{mm} \mathrm{Hg})$ & $1.01(1.00-1.01)$ & 0.042 & & \\
\hline Calculated Kt/V & $0.79(0.58-1.09)$ & 0.148 & & \\
\hline On HD (per year) & $1.00(0.98-1.03)$ & 0.820 & & \\
\hline Diabetes mellitus & $1.87(1.56-2.23)$ & $<0.001$ & & \\
\hline History of CHD & $2.44(2.03-2.93)$ & $<0.001$ & $2.15(1.76-2.62)$ & $<0.001$ \\
\hline Use of ACEi & $1.07(0.90-1.28)$ & 0.429 & & \\
\hline Use of $\beta$-blocker & $0.99(0.84-1.19)$ & 0.971 & & \\
\hline Use of sevelamer & $0.77(0.61-0.98)$ & 0.033 & & \\
\hline New centre & $0.85(0.69-1.05)$ & 0.137 & & \\
\hline hsCRP (mg/l) & $1.02(1.01-1.03)$ & $<0.001$ & & \\
\hline $\log \mathrm{CRP}$ & $1.25(1.17-1.34)$ & $<0.001$ & $1.23(1.06-1.23)$ & 0.001 \\
\hline
\end{tabular}

ApoA-1 (HR 0.63), calculated Kt/V (HR 0.78), years on HD (HR 1.02), diabetes (HR 1.70), history of CHD (HR 2.05) and hsCRP (HR 1.02) (table 2). There were univariate associations with TC (HR 0.92), however not with HDL-C or LDL-C. No significant associations were found with smoking status or BMI. In the corresponding multivariate analysis, the major determinants of MACE were: age (HR 1.03), phosphate (HR 1.50), albumin (HR 0.94), years on HD (HR 1.03), diabetes (HR 1.38), history of CHD (HR 1.54) and log CRP (HR 1.14). In the RSF model, the five most powerful risk factors for MACE were age, diabetes, hsCRP, phosphate and albumin (fig. 1).

\section{Atherosclerotic Cardiac Event}

Patients in this study experienced 524 atherosclerotic cardiac events (12.0 events per 100 patient-years). The univariate risk factors for this end point (table 3 ) were age
(HR 1.04), calcium (HR 0.65), phosphate (HR 1.26), albumin (HR 0.92), ApoB/ApoA-1 ratio (HR 1.46), ApoA1 (HR 0.48), diabetes (HR 1.87), history of CHD (HR 2.44), use of sevelamer (HR 0.77) and hsCRP (HR 1.02). In the multivariate analysis of this endpoint, six risk factors remained as independent predictors: age (HR 1.03), phosphate (HR 1.42), albumin (HR 0.96), ApoA-1 (HR $0.60)$, history of CHD (HR 2.15) and log CRP (HR 1.23).

\section{Death}

During the study, there were $648 \mathrm{CV}$ deaths with a corresponding event rate of 14.5 per 100 patient-years. By univariate analysis (table 4), risk factors were age (HR 1.04), calcium (HR 0.65), phosphate (HR 1.36), albumin (HR 0.91), ApoA-1 (HR 0.61), oxidized LDL (HR 0.99), calculated Kt/V (HR 0.63), diabetes (HR 1.83), history of CHD (HR 2.26), use of ACEi (HR 1.20), use of sevelamer 
Table 4. Risk factors for CV death: uni- and multivariate analyses

\begin{tabular}{|c|c|c|c|c|}
\hline Variable & $\begin{array}{l}\text { Univariate HR } \\
\text { ( } 95 \% \text { CI for HR) }\end{array}$ & $\mathrm{p}$ & $\begin{array}{l}\text { Multivariate HR } \\
\text { (95\% CI for HR) }\end{array}$ & $\mathrm{p}$ \\
\hline Age (per year) & $1.04(1.03-1.05)$ & $<0.001$ & $1.03(1.02-1.04)$ & $<0.001$ \\
\hline Female sex & $1.02(0.87-1.12)$ & 0.817 & & \\
\hline BMI & $1.00(0.99-1.02)$ & 0.586 & & \\
\hline Current smoker & $0.94(0.76-1.17)$ & 0.578 & & \\
\hline Calcium (mmol/l) & $0.65(0.45-0.93)$ & 0.018 & & \\
\hline Phosphate (mmol/l) & $1.36(1.19-1.56)$ & $<0.001$ & $1.56(1.36-1.80)$ & $<0.001$ \\
\hline Albumin $(g / 1)$ & $0.91(0.89-0.93)$ & $<0.001$ & $0.93(0.91-0.96)$ & $<0.001$ \\
\hline $\mathrm{TC}(1.3 \mathrm{mmol} / \mathrm{l})$ & $0.90(0.84-0.97)$ & 0.007 & & \\
\hline HDL-C (1.3 mmol/l) & $0.85(0.69-1.03)$ & 0.107 & & \\
\hline LDL-C $(1.3 \mathrm{mmol} / \mathrm{l})$ & $0.93(0.85-1.01)$ & 0.095 & & \\
\hline Triglycerides (0.6 mmol/l) & $0.92(0.85-0.99)$ & 0.044 & & \\
\hline ApoB/ApoA-1 ratio & $1.11(0.82-1.51)$ & 0.493 & & \\
\hline ApoB $(\mathrm{mg} / \mathrm{dl})$ & $0.90(0.65-1.23)$ & 0.498 & & \\
\hline ApoA-1 (mg/dl) & $0.61(0.45-0.81)$ & 0.001 & & \\
\hline Oxidized LDL (mmol/l) & $0.99(0.99-1.00)$ & 0.033 & & \\
\hline Haematocrit ratio & $0.07(0.01-0.35)$ & 0.001 & & \\
\hline Haemoglobin $(\mathrm{g} / \mathrm{l})$ & $0.99(0.99-1.00)$ & $<0.001$ & & \\
\hline $\mathrm{SBP}(\mathrm{mm} \mathrm{Hg})$ & $1.00(0.99-1.01)$ & 0.383 & & \\
\hline DBP (mm Hg) & $0.99(0.98-1.00)$ & 0.002 & & \\
\hline $\mathrm{PP}(\mathrm{mm} \mathrm{Hg})$ & $1.01(1.00-1.01)$ & 0.002 & & \\
\hline Calculated Kt/V & $0.63(0.47-0.84)$ & 0.002 & & \\
\hline On HD (per year) & $1.01(0.99-1.03)$ & 0.263 & & \\
\hline Diabetes mellitus & $1.83(1.56-2.14)$ & $<0.001$ & $1.32(1.08-1.61)$ & 0.006 \\
\hline History of CHD & $2.26(1.92-2.67)$ & $<0.001$ & $1.70(1.38-2.09)$ & $<0.001$ \\
\hline Use of ACEi & $1.20(1.03-1.41)$ & 0.018 & & \\
\hline Use of $\beta$-blocker & $0.99(0.85-1.16)$ & 0.912 & & \\
\hline Use of sevelamer & $0.76(0.62-0.94)$ & 0.013 & & \\
\hline New centre & $0.92(0.76-1.10)$ & 0.368 & & \\
\hline hsCRP (mg/l) & $1.02(1.01-1.03)$ & $<0.001$ & & \\
\hline $\log \mathrm{CRP}$ & $1.24(1.16-1.32)$ & $<0.001$ & $1.16(1.09-1.24)$ & $<0.001$ \\
\hline
\end{tabular}

(HR 0.76) and hsCRP (HR 1.02). There were also univariate associations with TC (HR 0.90), but not with HDL-C and LDL-C. In the multivariate analysis, six factors independently predicted CV death: age (HR 1.03), phosphate (HR 1.56), albumin (HR 0.93), diabetes (HR 1.32), history of pre-existing CHD (HR 1.70) and log CRP (HR 1.16).

\section{Discussion}

In patients receiving maintenance $\mathrm{HD}$, two large-scale prospective trials, AURORA and $4 \mathrm{D}$, have shown no benefit from statin treatment on a combined CV endpoint [8, 9], although post hoc analyses suggest an advantage in some subgroups [16]. The recently published SHARP study, which included 9,720 patients with CKD (of whom
3,023 were on maintenance dialysis therapy), reported that allocation to simvastatin plus ezetimibe was associated with a $17 \%$ reduction in major atherosclerotic events [17]. However, the majority of patients in SHARP were not on dialysis and analysis of the subgroup of patients on HD did not show a benefit of lipid-lowering therapy. Therefore, in the face of a limited efficacy of preventative strategies that are proven and well established in other patient groups, there is a pressing need to identify risk factors (and potential therapeutic targets) for CV disease in patients with end-stage renal disease receiving HD.

In this post hoc analysis of the AURORA study, traditional CV risk factors such as smoking status, BMI, LDL$\mathrm{C}$ or SBP were not associated with CV outcomes in HD patients, confirming previous reports $[18,19]$. In contrast, the present study showed that non-traditional risk factors that are specific to end-stage renal disease play an 


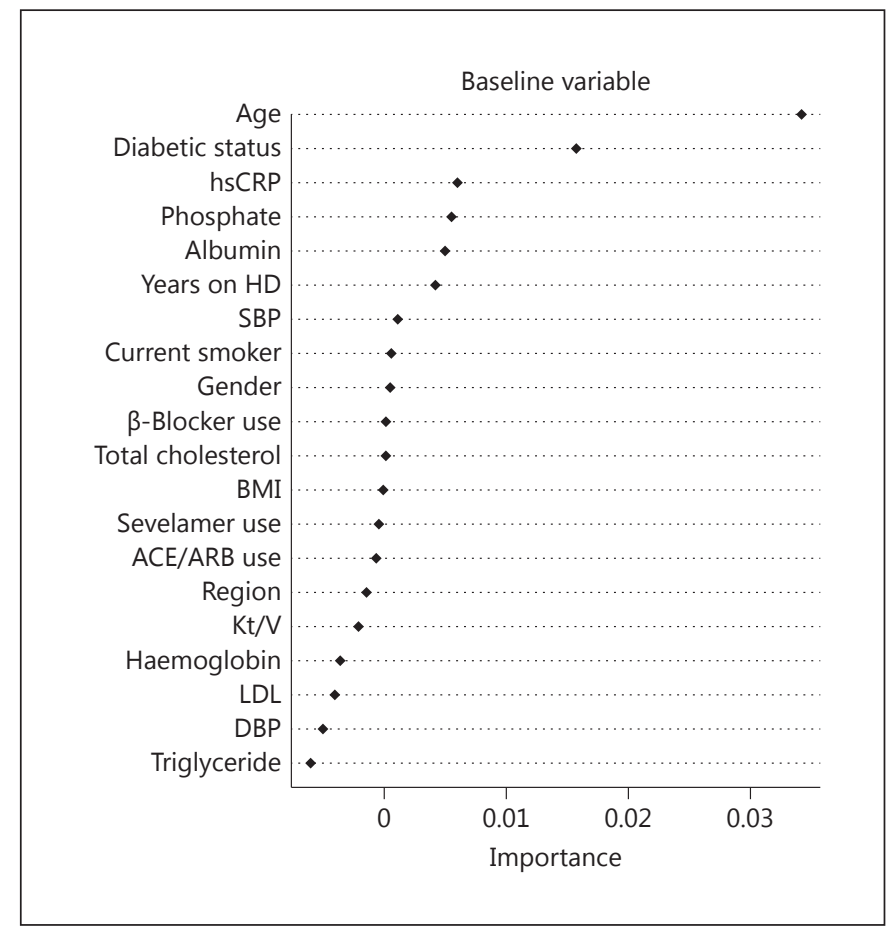

Fig. 1. Variable importance calculated by the RSF model for MACE.

important role for $\mathrm{CV}$ events in $\mathrm{HD}$ patients. In the multivariate analyses, older age, increased serum phosphate levels, lower serum albumin levels, preexisting CHD, years on HD, diabetes and increased CRP levels were independent risk factors for the primary endpoint MACE. Age was a risk factor for all pre-specified CV endpoints, including MACE, atherosclerotic cardiac events, and CV death. This confirms previous findings, such as those in an observational study of 34,741 dialysis patients by Roberts et al. [20] demonstrating that older age is a risk factor for CVD. Similarly, in a post hoc analysis from the randomized FOSIDIAL trial, the investigators also showed advanced age as a strong risk predictor for $\mathrm{CV}$ events in HD patients [21]. However, age is an unmodifiable risk factor, and the identification of potentially modifiable risk factors is of paramount importance. In the present study, we found that increased serum phosphate level was an independent risk factor for all endpoints. Various observational studies also suggest that serum phosphate level is a risk factor for CVD and mortality in HD patients $[12,13]$. For example, in a cohort study in 9,076 HD patients, an elevated phosphate level was identified as a predictor of mortality, independent of parathyroid hormone [12]. In another study with $12,833 \mathrm{HD}$ patients, higher

Cardiovascular Risk Factors in HD

Patients phosphate levels were associated with increased CV mortality [13]. This is consistent with functional studies that have shown elevated phosphate to be associated with impaired endothelial function in vitro and in vivo [22]. Endothelial dysfunction, in turn, is closely correlated with arterial stiffness, which is a powerful determinant of CV events in HD patients [23]. Furthermore, as a structural mechanism, high phosphate levels may contribute to vascular calcification, which is closely related to arterial stiffness [24]. The results from our current analysis support the notion that maintaining serum phosphate in the normal range should be a major treatment goal to prevent CVD in HD patients. On the other hand, it is possible that high phosphorus reflects non-compliance with diet, missed, or shortened dialysis treatments all of which can affect mortality.

Several clinical studies have demonstrated that elevated CRP levels and lower albumin levels are associated with increased CV mortality in HD patients [21, 25-28]. In our current analysis, these parameters were also independent risk factors for all pre-specified CV endpoints. The common occurrence of inflammation, malnutrition and atherosclerosis in HD patients has led to the suggestion of pattern of disease termed malnutrition, inflammation, and atherosclerosis (MIA) syndrome [29]. This syndrome has been associated with mortality in dialysis patients $[29,30]$. The FINE study, a prospective, randomised, controlled trial in 186 malnourished dialysis patients, demonstrated that improvement in the nutritional parameter pre-albumin, in response to nutritional supplements, was associated with a significant decrease in mortality [31]. Another randomised, controlled study from Recio-Mayoral et al. [32] in 76 CKD patients found that inflammation status correlates with endothelial dysfunction and the degree of atherosclerosis. Taken together with the findings of our large-scale study, these data suggest that interventions aimed at improving nutritional status and lowering the burden of inflammation, e.g. by using anti-cytokine therapy in HD patients [33], may be an effective strategy to prevent CV events in these patients. However, caution is warranted. Despite large reductions in hsCRP of about $50 \%$ in the AURORA study, we found no reduction in CV outcomes. It is possible that the link between inflammation and mortality is not a causal one. Measurements of conventional risk factors such as blood pressure were not made using ambulatory blood pressure recordings, therefore we are unable to dismiss the effects of such recordings on hard outcomes.

In conclusion, although $\mathrm{CV}$ risk in patients receiving $\mathrm{HD}$ is increased 10-20 times to that of the general popu- 
lation, the disease pattern, natural history and associated risk factors are very different. The AURORA trial demonstrated that rosuvastatin lowered LDL-C, but had no significant effects on CV events in nearly 3,000 HD patients followed for up to 4 years. We have used the AURORA trial database to explore risk factor relationships - for conventional and unconventional CV risk factors - for three independently validated CV endpoints. The results show that conventional risk factors, such as dyslipidaemia and smoking, have little impact on CV events, whereas elevated phosphate and evidence of inflammation are important potentially modifiable risk factors.

\section{Acknowledgements}

The authors thank all patients who participated in the AURORA study and are grateful to all investigators, study nurses and collaborators involved in patient recruitment, sample and data handling. This study could not have been performed without the sponsorship of AstraZeneca. A.S. was supported by a European Renal Association - European Dialysis and Transplant Association longterm fellowship.

\section{Disclosure Statement}

The authors have no conflicts of interest to disclose.

\section{References}

1 Yusuf S, Hawken S, Ounpuu S, et al: Effect of potentially modifiable risk factors associated with myocardial infarction in 52 countries (the INTERHEART study): case-control study. Lancet 2004;364:937-952.

2 Emberson JR, Whincup PH, Morris RW, Walker M: Re-assessing the contribution of serum total cholesterol, blood pressure and cigarette smoking to the aetiology of coronary heart disease: impact of regression dilution bias. Eur Heart J 2003;24:1719-1726.

3 Mendelsohn ME, Karas RH: The protective effects of estrogen on the cardiovascular system. N Engl J Med 1999;340:1801-1811.

4 Hubert HB, Feinleib M, McNamara PM, Castelli WP: Obesity as an independent risk factor for cardiovascular disease: a 26-year follow-up of participants in the Framingham Heart Study. Circulation 1983;67:968-977.

5 Baxi NS, Jackson JL, Ritter J, Sessums LL: How well do the Framingham risk factors correlate with diagnoses of ischemic heart disease and cerebrovascular disease in a military beneficiary cohort? Mil Med 2011;176:408413.

6 Hawranek M, Gasior M, Gierlotka M, et al: Progression of coronary artery atherosclerosis after acute myocardial infarction: an angiographic study. J Invasive Cardiol 2010;22: 209-215.

7 Foley RN, Parfrey PS, Sarnak MJ: Epidemiology of cardiovascular disease in chronic renal disease. J Am Soc Nephrol 1998;9(suppl):S16S23.

8 Fellstrom BC, Jardine AG, Schmieder RE, et al: Rosuvastatin and cardiovascular events in patients undergoing hemodialysis. N Engl J Med 2009;360:1395-1407.
9 Wanner C, Krane V, Marz W, et al: Atorvastatin in patients with type 2 diabetes mellitus undergoing hemodialysis. N Engl J Med 2005; 353:238-248.

10 Wanner C, Zimmermann J, Schwedler S, Metzger T: Inflammation and cardiovascular risk in dialysis patients. Kidney Int Suppl 2002;80:99-102.

11 Beddhu S, Kaysen GA, Yan G, et al: Association of serum albumin and atherosclerosis in chronic hemodialysis patients. Am J Kidney Dis 2002;40:721-727.

12 Block GA, Hulbert-Shearon TE, Levin NW, Port FK: Association of serum phosphorus and calcium $\times$ phosphate product with mortality risk in chronic hemodialysis patients: a national study. Am J Kidney Dis 1998;31: 607-617.

13 Ganesh SK, Stack AG, Levin NW, HulbertShearon T, Port FK: Association of elevated serum $\mathrm{PO}_{4}, \mathrm{Ca} \times \mathrm{PO}_{4}$ product, and parathyroid hormone with cardiac mortality risk in chronic hemodialysis patients. J Am Soc Nephrol 2001;12:2131-2138.

14 Drechsler C, Pilz S, Obermayer-Pietsch B, et al: Vitamin D deficiency is associated with sudden cardiac death, combined cardiovascular events, and mortality in haemodialysis patients. Eur Heart J 2010;31:2253-2261.

15 Zimmermann J, Herrlinger S, Pruy A, Metzger T, Wanner C: Inflammation enhances cardiovascular risk and mortality in hemodialysis patients. Kidney Int 1999;55:648658.

16 Holdaas H, Holme I, Schmieder RE, et al: Rosuvastatin in diabetic hemodialysis patients. J Am Soc Nephrol 2011;22:1335-1341.

17 Baigent C, Landray MJ, Reith C, et al: The effects of lowering LDL cholesterol with simvastatin plus ezetimibe in patients with chronic kidney disease (Study of Heart and Renal Protection): a randomised placebocontrolled trial. Lancet 2011;377:2181-2192.
18 Cheung AK, Sarnak MJ, Yan G, et al: Atherosclerotic cardiovascular disease risks in chronic hemodialysis patients. Kidney Int 2000;58:353-362.

19 Kalantar-Zadeh K, Block G, Humphreys MH, Kopple JD: Reverse epidemiology of cardiovascular risk factors in maintenance dialysis patients. Kidney Int 2003;63:793-808.

20 Roberts MA, Polkinghorne KR, McDonald SP, Ierino FL: Secular trends in cardiovascular mortality rates of patients receiving dialysis compared with the general population. Am J Kidney Dis 2011;58:64-72.

21 Kessler M, Zannad F, Lehert P, et al: Predictors of cardiovascular events in patients with end-stage renal disease: an analysis from the fosinopril in dialysis study. Nephrol Dial Transplant 2007;22:3573-3579.

22 Shuto E, Taketani Y, Tanaka R, et al: Dietary phosphorus acutely impairs endothelial function. J Am Soc Nephrol 2009;20:1504-1512.

23 Blacher J, Guerin AP, Pannier B, Marchais SJ, Safar ME, London GM: Impact of aortic stiffness on survival in end-stage renal disease. Circulation 1999;99:2434-2439.

24 London GM, Marchais SJ, Guerin AP, Metivier F: Arteriosclerosis, vascular calcifications and cardiovascular disease in uremia. Curr Opin Nephrol Hypertens 2005; 14:525-531.

25 Kovesdy CP, Kalantar-Zadeh K: Review article: Biomarkers of clinical outcomes in advanced chronic kidney disease. Nephrology (Carlton) 2009;14:408-415.

26 Wanner C, Metzger T: C-reactive protein a marker for all-cause and cardiovascular mortality in haemodialysis patients. Nephrol Dial Transplant 2002;17(suppl 8):29-32, 39-40. 
27 Kato A, Takita T, Furuhashi M, Maruyama Y, Hishida A: Comparison of serum albumin, Creactive protein and carotid atherosclerosis as predictors of 10-year mortality in hemodialysis patients. Hemodial Int 2010;14:226-232.

28 Snaedal S, Heimburger O, Qureshi AR, et al: Comorbidity and acute clinical events as determinants of C-reactive protein variation in hemodialysis patients: implications for patient survival. Am J Kidney Dis 2009;53: 1024-1033.
29 Pecoits-Filho R, Lindholm B, Stenvinkel P: The malnutrition, inflammation, and atherosclerosis (MIA) syndrome - the heart of the matter. Nephrol Dial Transplant 2002; 17(suppl 11):28-31.

30 De Mutsert R, Grootendorst DC, Axelsson J, Boeschoten EW, Krediet RT, Dekker FW: Excess mortality due to interaction between protein-energy wasting, inflammation and cardiovascular disease in chronic dialysis patients. Nephrol Dial Transplant 2008;23: 2957-2964.

31 Cano NJ, Fouque D, Roth $\mathrm{H}$, et al: Intradialytic parenteral nutrition does not improve survival in malnourished hemodialysis patients: a 2-year multicenter, prospective, randomized study. J Am Soc Nephrol 2007;18: 2583-2591.
32 Recio-Mayoral A, Banerjee D, Streather C, Kaski JC: Endothelial dysfunction, inflammation and atherosclerosis in chronic kidney disease - a cross-sectional study of predialysis, dialysis and kidney-transplantation patients. Atherosclerosis 2011;216:446-451.

33 Hung AM, Ellis CD, Shintani A, Booker C, Ikizler TA: IL- $1 \beta$ receptor antagonist reduces inflammation in hemodialysis patients. J Am Soc Nephrol 2011;22:437-442. 